\title{
NUCLEAR STRUCTURE REFERENCES CODING MANUAL
}

\author{
S. Ramavataram and C.L. Dunford
}

February 1984

\section{NOTIGE}

POBTIBRS OF THIS REPOHT ARE ILLEGIBLE.

4 wos been reproduced from the best arallable copy to permit the broadest possille evallability.

INFORMATION ANALYSIS CENTER REPORT

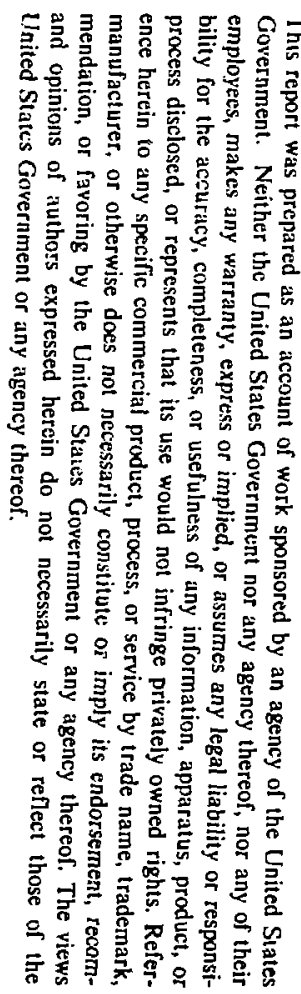




\section{DISCLAIMER}

This report was prepared as an account of work sponsored by an agency of the United Stateg Government. Neither the United States Government nor any agency thereof nor any of their employees, nor any of their contractors. subcontractors. or their employees, makes any warranty, express or implied, or assumes any legal liability or responsibility for the accuracy, completeness, or usefulness of any information. apparatus, product, or process disclosed, or represents that its use would not infringe privately owned rights. Reference herein to any specific commercial product. process. or service by trade name. trademark, manufacturer, or otherwise, does not necessarily constitute or imply its endorsement, recommendation, or favoring by the United States Government or any agency, contractor or subcontractor thereof. The views and opinions of authors expressed herein do not necessarily state or reflect those of the United States Government or any agency, contractor or subcontractor thereof.

Printed in the United States of America

Available from

National Technical Information Service

U.S. Department of Commerce

5285 Port Royal Road

Springfield, VA 22161

NTIS price codes:

Printed Copy: A04; Microfiche Copy: A01 


\section{Contents}

I Introduction

II Structure of the Nuclear Structure References File

III Keywords

IV H terature Coverage

V Appendices 
This manual is intended as a guide to Nuclear Structure References (NSR) compilers. The basic conventions followed at the National Nuclear Data Center (NNDC), which are compatible with the maintenance and updating of and retrieval from the Nuclear Structure References (NSR) file, are outlined.

In Sec. II, the structure of the NSR file such as the valid record identifiers, record contents, text fields as well as the major TOPICS for which 〈KEWORDS〉 are prepared are ennumerated. Relevant comments regarding a new entry into the NSR file, assignment of 〈KEYNO 〉, generation of 〈SELECTRS〉 and linkage characteristics are also given in Sec. II. In Sec. III, a brief defintion of the Keyword abstract is given followed by specific examples; for each TOPIC, the criteria for inclusion of an article as an entry into the NSR file as well as coding procedures are described. Authors submitting articles to Journals which require Keyword abstracts should follow the illustrations in Sec. III. The scope of the literature covered at NNDC, the categorization into Primary and Secondary sources etc. is discussed in Sec. IV. Useful information regarding permitted character sets, recommended abbreviations etc. is given under Sec. $V$ as Appendices. 


\section{Structure of the NSR File}

The NSR file* originated at the Nuclear Data Project (NDP) as a program for systematic evaluation of Nuclear Strcuture data. Each entry in this computer master file ts characterized and uniquely identified by a keynumer, Topic and Keywords. It has been used since 1969 to produce bibliographic citations for special topics; in particular periodic additions to the file are retrieved and published as the "Recent References" issues of the Nuclear Data Sheets. In October 1980, the maintenance and updating of the NSR file becane the responsibility of NNDC at Brookhaven National Laboratory. The basic contents of the NSR file remalned unchanged as a result of the transfer to NNDC. The file uses the ADSEP ${ }^{+}$format with logical records initiated by a ten character identifier. The file contains 80 character physical records with the start of each logical record coinciding with the beginning of a physical record.

The legal record identifiers are:

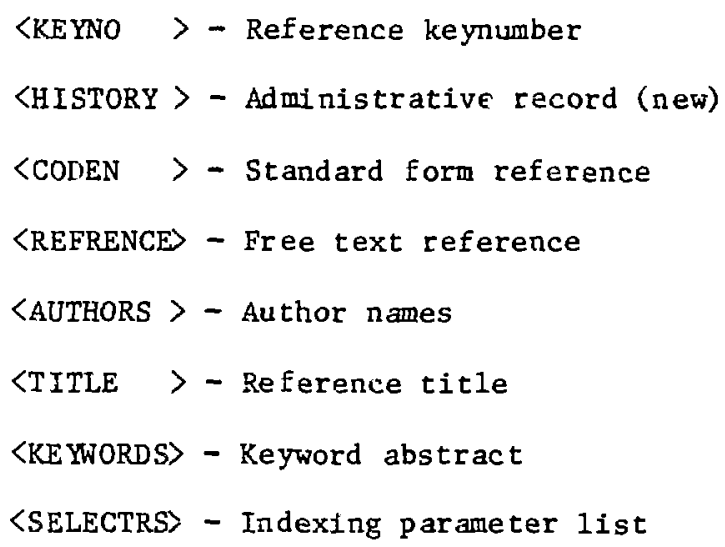

W.B. Ewbank, "The Nuclear Structure References (NSR) File," ORNI-5397 (1978). +A.A. Brooks, "An Automated Data Set Editing Program," CTC-34 (1970) 
Only these record types appear in the file and they appear in the above order. Only one record of each type appears in the file for each reference, except for 〈KEYWORDS〉 and 〈SELECTRS〉 which will be repeated for each major category (i.e., NUCLEAR REACTIONS, NUCLEAR STUCTURE, etc.) under which the reference is indexed.

\section{A. 〈KEYNO >}

The record contents are unchanged. The keynumber has six characters. The first two, the publication year; the second two, the first two letters of the first author's last name; and the flnal two a unique identifier (2 digits for a Primary reference or 2 letters for a Secondary reference). The only change is that the keynumbers are upper case as shown in example below.

$$
\begin{aligned}
& \text { 76LA03 - Primary } \\
& \text { 76LAZY - Secondary }
\end{aligned}
$$

For an Initial entry prepared in the "compled" mode (see <HISTORY> record below) the keynumber will have flve characters. The first four have the same significance as above. The last character is $\mathrm{P}$ sor Primary source, $S$ for Secondary source. Thus in the update input file the record would be

$$
\begin{aligned}
\text { <KEYNO } & >76 \mathrm{LAP} \\
\text { or } & <\mathrm{KEYNO}>76 \mathrm{LAS}
\end{aligned}
$$

The program which updates the NSR data base will assign the complete keynumber for the reference. 


\section{B. 〈HISTORY >}

This is a new record. It contairs a single character code followed by a date in the form YYMMD.

The possible codes are:

$$
\begin{aligned}
& \text { A - added } \\
& M \text { - modified } \\
& D \text { - deleted } \\
& C \text { - compiled (for use by NSR compilers preparing a new entry) }
\end{aligned}
$$

Examples: <HISTORY >A800211 New reference entry after update of NSR data base <HISTORY >M791122 Modified reference entry <HISTORY >D800101 Deleted reference entry <HISTORY >C840101 New reference entry prepared for NSR data base update

\section{C. 〈CODEN >}

The record contents are essentially unchanged. The fjeld consists of a reference-type code of not more than 70 characters terminating with a blank. The short form of the reference then follows.

The permitted reference types are:

$\begin{array}{ll}\text { JOUR } & \text { - Journal } \\ \text { CONF } & \text { - Conference } \\ \text { REPT } & \text { - Report } \\ \text { BOOK } & \text { - Book } \\ \text { PC } & \text { - Private Communication } \\ \text { THESIS } & \text { - Thesis } \\ \text { PREPR.LNT } & \text { - Preprint }\end{array}$


The only change is the introduction of the code JouR for journal. Previously there was no reference type code preceding the CODEN for a journal. Foz Primary sources (Journals) the KCODEN > format is standard. A list of Journals scanned at NNDC together with the internationally approved <CODEN > is attached (Sec. V Appendix C). A typical <CODEN > entry given below:

LCODEN >JOUR PRVCA 18424

represents an article from Phys. Rev. C18, Page 424.

For Secondary sources except when the reference type is JOUR, the format depends on the reference type. Typical <CODEN entries are considered in sequence below:

JOUR: Abstracts of Physical Society meetings and Theses are coded under this category:

CCODEN >JOUR CODEN \# \#, \#, First Author's Last name

Example: <CODEN >JOUR BAPSA 18720, KK12,Nawrocki

Volume No. Page No. Abstr. No. .

Example: <CODEN >JOUR DABBB 41,4162, Liu

Volume No. Page No. 
CONF: Generally all contributed papers with new data are coded. Invited talks and reviews are inclued only if they discuss new data relevant to NSR. <CODEN >CONF Location held(Subject), P非, First Author's 1 ast name

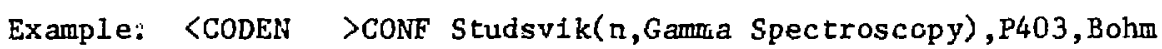
If the Reference was a contributed paper from Proceedings of the Conference published separately from Invited Talks:

E:ample: (CODEN >CONF Tokyo( Nuclear structure) Proc, P403, Bohm If the Reference was from the Contributions to the Conference published separately from Invited Talks:

Example: (CODEN >CONF Tokyo( Nuclear Structure) Contr1b,P403, Bohm If conference Proceedings had a Report Code assigned: Example: <CODEN >CONF Leysin Vo12 P1093, CERN-70-30

Note: The above example also illustrates how multi-volumed sources are coded. The Volik appears immediatly before the page specificiacion.

Conferences on Nuclear Spectroscopy and Nuclear Structure held in the USSR Example: <CODEN >CONF Erevan, P7 1, Burmistov 
REPT:

$<$ CODEN $>$ REPT CODE- 作,P非,First Author's last name
Example: $<$ CODEN >REPT INDC (CCP)-164/1,P9, Skaras tov

If References are from Annual Reports of Labortories without specific :ode number:

Example: <CODEN >REPT Univ. Arkansas Nuc1. Chem. Ann. Rept.,P4,Kantele

If Reference is taken from Annual Reports of Laboratories whth assigned code: Example: <CODEN >REPT MSUCL 1978 Annual, P50, Daly

BOOK:

<CODEN >BOOK Title/Abbreviated Title, Publisher

Example: <CODEN >BOOK Table of Isotopes, 7 th Ed., John Wiley and Sons

$\underline{P C}:$

<CODEN >PC First Author's initials separated by 1 space followed by last name

Example: <CODEN >PC E Spejewski

If Private Communication was dated:

Example: CCODEN >PC E Spejewski,5/28/80

If Private Communication was quoted by another reference already in NSR file: Examle: <CODEN >PC E Sp zjewski, quoted by $81 P 002$

- If quoted Private Commication was dated:

Example: <CODEN >PC E Spejewski,quoted by 81P002 5/13/81 


\section{<CODEN >THESIS Author's Initials separated by 1 space followed by 1 ast name, Affiliation}

Example: <CODEN >THESIS W Roney,Univ New Mexico

If Thesis has been assigned a Report Number:

Example: <CODEN >THESIS W Roney, Univ New Mexico,LA-4198

If Thesis abstract is published in Dissertation Arstracts

Example: <CODEN >THESIs W Roney,Univ New Mexico,DABBB 322339

Volume No. Page No.

\section{PREPRINT:}

Preprints included in NSR file generally have a code number like reports. Example: <CODEN >PREPRINT PPP/4-81,Ajzenberg-Selove

If preprint has no code number but is dated and author's name is available, then <CODEN> will be as in example given below.

Example: CCODEN >PREPRINT Ajzenberg-Selove, $M / D / Y$

D. 〈REFRENCE〉, 〈AUTHORS >, 〈TITLE >

These are free text fields with no changes in structure or content. All primary references must have these three records. They can exceed 70 characters. The <REFRENCE $>$ fleld for Primary sources is standardized. For the <CODEN > example given above (Sec. IIC), this will be <REFRENCEP Phys. Rev. Cl 8, 424 (1980) 
If an Erratum is published for this Reference in a subsequent issue of the Journal the entry will be modified as:

〈REFRENCE〉Phys.Rev. Cl8, 424 (1980); Erratum Phys.Rev. C19, 530 (1981)

For the Russian Journals for which English Translations are avatlable this information is included in the LREFRENCE field. A list of the Journal CODEN together with the modification to the 〈REFRENCE〉 field is given below. The modification follows the original information in this field as $i n$ the case of an Erratum discussed above.

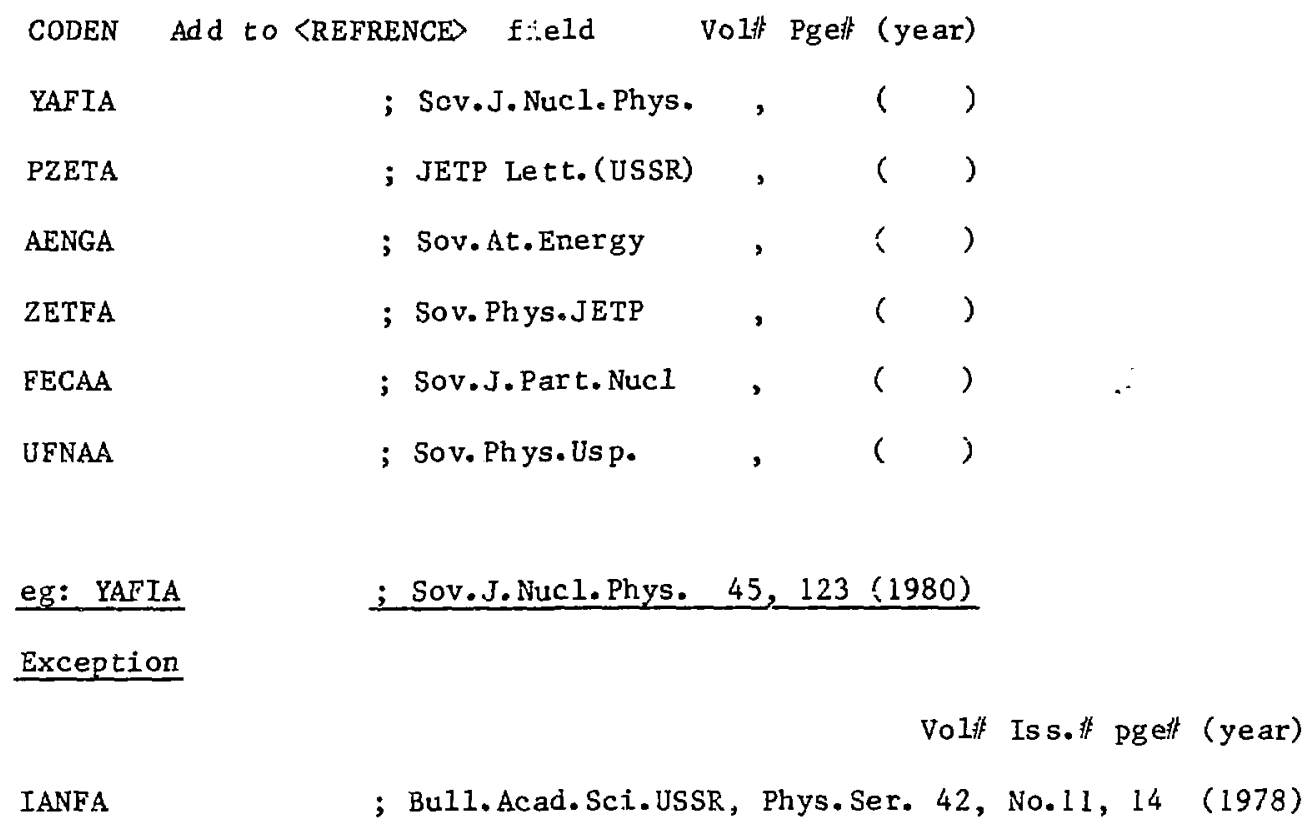

For Secondary sources classified as JOUR, the format is standard. For all the others it is nonstandard. The 〈REFRENCE) fields for the examples discussed in the (CODEN section (Sec. IIC) are considered in sequence. 
JOUR:

CODEN:BAPSA

〈REFRENCE Bul1. Am. Phys. Soc. 18, No.4, 720, KKl2 (1980)

Issue Number

CODEN :DABBB

<REFRENCE DIss. Abst.Int. 41B, 4162 (1980)

CODEN : PHCAA

〈REFERENCE〉Phys.Can. 33, No.3, p.9, CF9 (year)

CONF:

〈REFRENCE〉Intern. Conf. Neutron Capture Gamma-Ray Spectroscopy, Studsvik, p.403（ 1969)

〈REFRENCE〉Proc. Intern. Conf.Nuc1. St ruc. , Tokyo, p.403 (1969)

If Editors and Publishers are mentioned then before p. 〈REFRENCE field add:

, A.Arima, K. Ogata Eds., P1enum Press, New York, p.403 (year)

Editors Publishers location year published

If conference date is different from actual date of publication of proceedings, then use the following format:

〈REFRENCE Proc. In tern. Conf. Nuc1. St ruct., Tokyo (1969), A. Arima, K. Ogata, Eds., Plenum Press, New York, p. 403 (1970) 
If the Reference was taken from Contributions to the International Conference then:

$\langle$ REFRENCE〉Contrib. In tern. Conf. Nucl. St ruct., p.403 (1969)

If Conference Proceedings had a Report Code:

〈REFRENCE〉Proc. In tern. Conf.Prop.Nucle1, Leysin, Switzerland, Vol. 2, p.1093 (1 970); CERN-70-30 (1970)

For Conferences held in the USSR on Nuclear Spectroscopy and Nuclear Structure:

〈REFRENCE〉Program and Theses, Proc.19th Ann. Conf.Nucl. Spectrosc. Struct. At. Nu clei, Erevan, p.71 (1969)

REPT:

If a Report has code number assigned:

Exainie: 〈REFRENCE〉INDC(CCP)-164/L, p.9 (1981)

If Reference is from Annual Reports of Laboratories withoul specific Code Number:

Example: 〈REFRENCE Univ. Arkans as, Nuc1. Chem. Res., Ann.Rept., p.4 (1963)

If Laboratories have specific code:

Ex ample: <REFRENCEDMich. St ate Univ, Cyclotron Lab. Ann. Rept., p.50 (1978)

where CODE MSUCL has been expanded in 〈REFRENCE〉 field 
BOOK:

〈REFRENCE TItle, Publisher, Address (year)

Example: 〈REFRENCE>Table of Isotopes, 7 th Ed., John Wiley and Sons, Inc., Ne

W York (1978)

PC:

Example: 〈REFRENCE〉Priv, Comm. (1980)

If Private Communication was dated:

Example:〈REFRENCE〉Priv. Comm。（May 1980)

If Private Communication was quoted by another reference already in NSR file: Ex ample: 〈REFRENCE〉Priv. Comm, quoted by 81 P002 unpublished (1979)

\section{THESIS :}

〈REFRENCE〉Thesis, Affiliation (year)

Example: 〈REFRENCE〉Thesis, Univ. New Mexico (1969)

If Thesis has been assigned Report Number:

Example: 〈REFRENCE>Thesis, Univ. Hew Mexico (1969); LA-4198 (1969)

If Thesis abstract is published in Dissertation Abstracts

Example: 〈REFRENCE〉Thesis, Univ. New Mexico (1969); Diss. Abst. Int. 32B, 2229 (1969) 


\section{PREPRINT:}

If PREPRINT has code number

〈REFRENCE〉CODE-\# (year)

Examp le: 〈REFRENCEDPPP/4-81 (1981)

If there is no code number

Example: 〈REFRENCE〉Priv. Comr. (1981)

\section{E. 〈KE YWORDS〉}

The allowed major TOPICS are:

NUCLEAR REACTIONS

RADIOACTIVITY

NUCLEAR STRUCTURE

NUCLEAR MOMENTS

COMPILATION

ATOMTC PHYSICS

ATOMIC MASSES

The details for the preparation and coding of 〈KEYWORDS〉 are given in Sec. III.

F. 〈SELECTRS〉

This field has been totally redesigned to improve processing and retrieval capability. It is an all upper case field with entries for each indexable parameter for the reference.

The format of each entry is as follows:

(parameter type):(parameter value);(link variable). 
Entries are placed successively in the record separated by a single blank. The valid parameter types are:

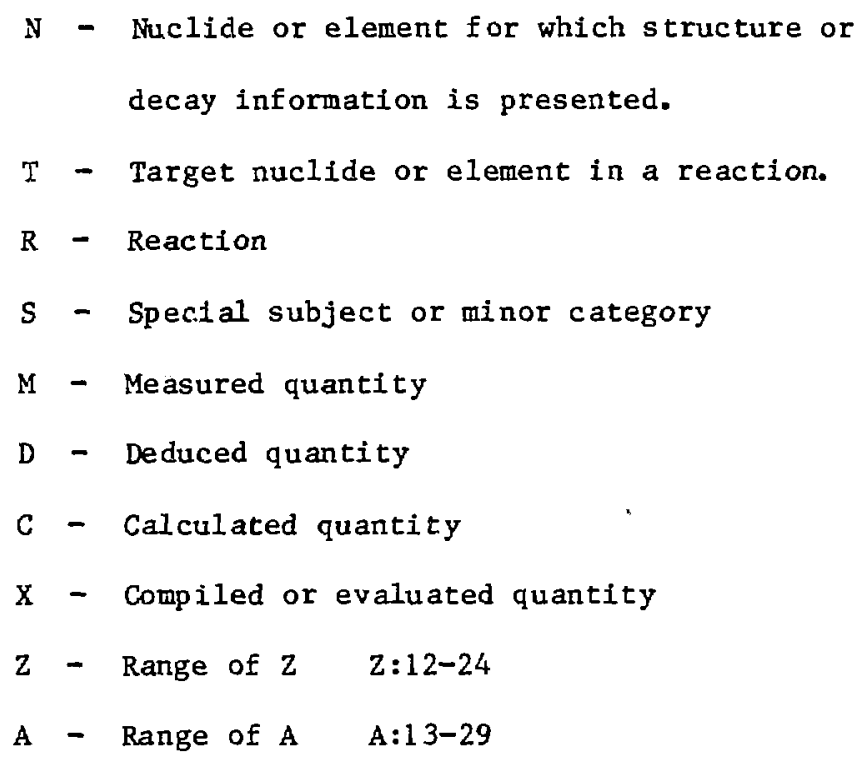

Dictionaries of valid entries (parameter values) are available on request.

A typical 〈SELECTRS> field generated by the entry programme for Radioactive decay of $249^{\circ} \mathrm{CF}$ may appear as

〈SELECTRS〉N2 49CF;A. M:G-SPECTRA; A. M:A-DECAY;A. N:245CM;B. D:Tl/2;B .

where the link variable $A$ is for the Parent nucleus for which measurements were made while $\underline{B}$ is for the Daughter nucleus whose properties were deduced. Another example glven below is generated when the angular distribution of outgoing protons is measured in the reaction ${ }^{16} 0(\mathrm{n}, \mathrm{p})$ 
〈SELECTRS〉T:I60;A. R:(N,P);A. M:DSIGMA,A.

G. The character sets used in the NSR file are given in Sec. V Appendix A. A. General

\section{Keywords}

a) Definition: A mlniabstract of essential information from publication. It is headed :by a TOPIC and contalns brief sentences describing what was measured/calculated/analyzed/compiled followed by $\therefore$ what was deduced. Additional details such as experimental techniques, theoretical formalisms, etc., are given as comments at the end. The keywords string should terminate with a period. Specific punctuation rules should be followed. These rules are illustrated by examples under each topic in Sec. III B.

b) Recommended Abbreviations: The abbreviations and symbols used are given in the introduction and inside back cover of each Recent References issue of Nuclear Data Sheets. These are summarized in Sec. V, Appendix B.

c) General Keywords Format:

〈KE WORDS〉PARAMETER 1 PARAMETER 2; PARAMETER 3; PARAMETER 4; PARAMETER 5. PARAM ETER 6 PARAMETER 7.

\section{PARAMETER 1: Topic Specification:}

Major Topic: Example: NUCLEAR REACTIONS

Major Topic, Minor Topic: Example: ATOMIC PHYSICS, Mesic Atoms 
PARAMETER 2: String of Nuclei investigated. This item is specified for all Topics. The delimiter ';' is used for all topics except NUCLEAR REACTIONS/ATOMIC PHYSICS. For these two cases PARAMETER 3 follows immediately without any punctuation mark.

PARAMETER 3: (projectile, outgoing particle), projectile energy, energy range, energy units. This parameter is specified only for, NUCLEAR REACTIONS/ATOMIC PHYSICS entries. 4

PARAMETER 4: specification of measured/calculated/analyzed/compiled quantities. A space precedes this Parameter specification.

PARAMETER 5: specification of deduced quantities of : a general nature.

PARAMETER 6: specification of deduced Nuclear Properties. String of Nuclei followed by deduced

PARAMETER 7: comments relevant to Experimental and/or Theoretical techniques.

All keywords must terminate with '.' as the delimi ter. The 'typical entry' ex.mples given in Sec. III B correspond exactly to the Keypunch input to the NSR file. Exactly 80 characters are allowed per line in the Keyword string; punctuation marks and blank spaces are also as shown in examples. 
B. Specification of Topic, Inclusion Criteria, Coding Procedures, Typical

\section{Entries}

\section{Topic: NUCLEAR REACTIONS:}

\section{Inclusion Criteria}

Hadron, 1ight-, heavy-ion, electron, photon, meson induced reactions, flssion are included. Projectlle energy has to be within the nonrelativistic limit. For proton-induced reactions the upper limit for Incident energy is set at $1 \mathrm{GeV}$. Projectile energy or related quantties in keyword string can be specified in any of the following ways:

1) $\mathrm{E}=--\mathrm{HeV}$; implies projectile energy was specified in the article in the laboratory frame.

11) $E(\mathrm{~cm})=--M e V$; this is used when the researchers have quoted projectile energy in center-of-mass system.

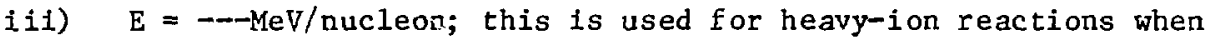
in the article the laboratosy energy is not specified anywhere in units of $\mathrm{MeV}$.

iv) E at - - MeV/c; this notation is used when projectile nomentum is specified.

v) E at rest; used for meson capture reactions.

vi) $E>$

are also used when energy range is only approyimately E< defined in the article

$E \approx$

vii) $\mathrm{E}=$ threshold $---\mathrm{MeV}$;

viii) E not given; used when the projectile energy is not specified anywhere in the article. 


$$
\begin{aligned}
& E=\text { reactor spectrum } \\
& \text { 1x) For neutron induced reactions } \mathrm{E}=1 \mathrm{ow} \\
& E=\text { slow can be used } \\
& E=f a s t \\
& \mathrm{E}=\text { thermal } \\
& \text { x) For charged particle projectiles } \mathrm{E}=\text { tandem can be used } \\
& E=\text { cyclotron }
\end{aligned}
$$

Coding Procedure

1) under this topic a string of target nuclei may be included, as well as different reactions induced by a given projectile. The residual nuclei can also be included as a string.

〈KE WWORDS〉NUCLEAR REACTIONS $\{+12\},\{+13\} c(d, d),(d, p), E=0.4-0.85 \mathrm{HeV}$; measured |s(E, q $)$; deduced optical-model parameters. $\{+13\},\{+14\} \mathrm{C}$ levels deduced S. E nriched targets. DWBA analysis.

Note:

The reaction string for given projectile energy is terminated by ', ' The delimiter ' $;$ ' is used to indicate that measured/calculated/ analyzed/compiled quantities will follow. The delimiter ';' is used to separate a general deduction such as the determination of optical model parameters from any specific nuclear properties that may be deduced. The delimiter '.' which is the next punctuation mark in this example indicates that deductions regarding the nuclei ${ }^{13,14} \mathrm{C}$ will follow. Finally, the comment pertaining to experiment 'Enriched target' is separated from the theoretical procedure 'DWBA analysis' by a '.' as a delimiter. 
ii) Different reactions used to reach a given set of final nuclei with measured and deduced quantities being the same should be coded as in the following:

〈KEWORDS〉NUCLEAR REACTIONS $\{+117\} \operatorname{Sn}(\mid a, n), E=1 \epsilon, 18,20 \mathrm{MeV} ; \mid+119\} \operatorname{Sn}(\mid a, n), E=18$ $\mathrm{MeV} ;\{+114\} \mathrm{Sn}(\mid a, 2 n), E=22,24 \mathrm{MeV} ;\{+116\} \mathrm{Sn}(\mid a, 2 n), E=22 \mathrm{MeV} ;\{+106\} \operatorname{Pd}(\{+12\} \mathrm{C}, 2 \mathrm{n}$ ), $E=58 \mathrm{MeV} ;\{+110\} \operatorname{Pd}(\{+13\} \mathrm{C}, 3 \mathrm{n}), E=40,45,49,52 \mathrm{MeV} ;\{+110\} \mathrm{Cd}(\{+13\} \mathrm{C}, 3 \mathrm{n}), E=52 \mathrm{Me}$ $\mathrm{V}$; measured $|g| g-\operatorname{coin},|g(\mid q)| s,(E \mid q)$. $\{+116\},\{+118\},\{+120\},\{+122\} \mathrm{Te},\{+120\} \mathrm{Xe} d$ educed levels,J, P. Enxiched targets,Ge(L1; detectors.

iii) Different reactions, different measured quantities; coding should be as given below.

$\langle$ KE WWORDS〉NUCLEAR REACTIONS $\{+12\},\{+13\} C(\{+32\} S,\{+32\} S),(\{+28\} S i,\{+28\} S i), E=55-$ $99 \mathrm{MeV}$; measured $\mid \mathrm{s}(\mid \mathrm{q}=180\{+0\}, \mathrm{E}) ;\{+12\} \mathrm{C}\{+32\} \mathrm{s},\{+32\} \mathrm{S}), \mathrm{E}=65-99 \mathrm{MeV}$; measured | $s(\mid q)$. Parity dependent potential,optical model. iv) Fission reactions are included in the following format.

$\langle K E$ YWORDS $>$ NUCLEAR REACTIONS $\{235\} \mathrm{U}(\mathrm{n}, \mathrm{F}), \mathrm{E}=1-1000 \mathrm{eV}$; measured $| \mathrm{S}(\mathrm{E})$, fission fragment-fragment $(\mid q)$.

Note: for proper indexing under the subject fission, the word fission has to appear in the keyword string. The minor topic specification is no longer allowed for NSR entries.

v) Theoretical work on nuclear reactions is coded exactly like an experimental abstract except that measured is replaced by calculated. Deduced information is included if available 
$\langle$ KE WORDS $\rangle$ NUCLEAR REACTIONS $\{+12\} C(\{+6\} L-1+6\} L-1),(\{+6\} \mathrm{Li}, \mathrm{d}), \mathrm{E}=13 \mathrm{MeV}$; calcul ated $\mid s(\mid q)$. Optical, DWBA models.

vi) NSR file entry program now automatically indexes residual nuclei in a nuclear reaction when the outgoing particles are fully specified. In cases where this is not possible, such as in the case of spallation, neutron, neutron plus charged particle evaporation reactions, residual nuclei will be indexed if the keyword string is written as shown in the example below, NUCLEAR REACTIONS $\{+54\} \mathrm{Fe}(\{+58\} \mathrm{Ni}, \mathrm{X})\{+72\} \mathrm{Zn} /\{+73\} \mathrm{Zn} /\{+61\} \mathrm{Fe} /+62 \mathrm{Fe}$, $E=108 \mathrm{MeV}$; measured residuals production/s. Activation technique

In the above example, the residual nuclei $70,73_{\mathrm{nn}}, 61,62_{\text {Fe }}$ produced in the spallation reaction are specified just before the projectile energy part of Parameter $3(\mathrm{P} 18)$ is specified. The delimiter ' $/$ ' is used to allow the indexing program to pick out the residual nuclei in sequence.

\section{Topic: RADTOACTIVITY}

Inclusion Criteria: $\gamma^{-}, \beta-, \alpha-d e c a y$, delayed-particle emission, internal conversion, spontaneous fission related information is included. For a given nuclide, all possible decay modes are specified. If there is a string of nuclei, all nuclei with a given decay mode can be burched together and the decay mode specified just before the last nuclide. This will result in proper indexing and economy of indexing variables 
generated in the 〈SELECTRS> string. This is illustrated in the examples given below.

Coding Procedure: The 1 tems measured/calculated/analyzed/and deduced are separated by delimiters (punctuation marks) analogous to NUCLriAR REACTIONS entries

i) 〈KE WORD $>$ RADIOACTIVITY $\{+62 \mathrm{~m}\} \mathrm{Co}(\beta+),(\mathrm{EC})$; weasured $\mathrm{T}\{-1 / 2\}, E|\mathrm{~b},| \mathrm{b}|\mathrm{g}-\mathrm{coin},| \mathrm{g}$ CP; deduced $\log f t, Q$. $\{+62\}$ Ni deduced levels, J,ICC. Ge(LI) detector.

Note: the delimiter ';' is used after Parent Nucleus spectfication while the delimiter '.' is used before Daughter Nucleus specification.

ii) Parent Nuclei should follow in a string after Topic is specified. Daughter nuclei should also follow in sequence if same quantities are deduced.

〈KE WORDS〉RADIOACTIVITY $\{+230\} \mathrm{Ra}, \mid+230\} \mathrm{AC}(\mid \mathrm{b}\{+-\mid)$; measured $\mathrm{E}|\mathrm{g}, \mathrm{I}| \mathrm{g}, \mathrm{E} \mid \mathrm{b}$; deduced $\log \mathrm{ft} .\{+230\} \mathrm{Ac},\{+230\}$ Th deduced levels.

ii1) Theoretical work under this topic is coded as:

〈KE YWORDS>RADIOACTIVITY $\{+186\} \operatorname{Re}(\mid \mathrm{b}\{+\},(\mathrm{EC}) ;\{+188\} \operatorname{Re},\{+176 \mathrm{~m}\} \operatorname{Lu}(\mid \mathrm{b}\{+\}) ;$ calculated $\log \mathrm{ft}, \mathrm{b}$-decay strength function.

iv) General deductions as well as Daughter Nuclear properties deduced: 
RADIOACTIVITY $\{+227\}$ Th $(\mid a)$; measured $|\mathrm{g}|(\mathrm{q}, \mathrm{H})$ in $\mathrm{NI}, \mathrm{Co}, \mathrm{Fe}$; deduced hyperfine fields - $\{+223\}$ Ra level deduced $g$.

v) Spontaneous Fission:

〈RE WORDS〉RADIOACTIVITY $\{+252\} C f(S F)$; measured $\{\mathrm{T}-1 / 2\}$, (f ragment) $\mid \mathrm{g}-\mathrm{coin}$.

vi) Coding with identification of method, reaction etc. used in producing activity.

〈KE YNORDS〉RADIOACTIVITY $\{+173\} \operatorname{Lu}(\mathrm{EC})$ [f $\mathrm{rom} \operatorname{Ta}(\mathrm{p}, \mathrm{X}), \mathrm{E}=1 \mathrm{GeV}$ ]; measured --etc.

$\langle$ KE YORDS>RADIOACTIVITY $\{+188\} A$ Au(EC), $(\mid \mathrm{b}\{++\})$ [from on-line separator]; measured ---etc.

TOPic: NUCLEAR STRUCTURE

Inclusion Criteria:

Any model calculation of levels, electromagnetic transition probabilities, multipole moments, nuclear form factors, giant resonance characteristics, nuclear systematics, binding energies, etc.

Coding Procedures:

i) 〈KE WORDS〉NUCLEAR STRUCTURE $\{+14\},\{+15\} \mathrm{N},\{+16\},\{+17\},\{+18\} 0 ;$ calculated s Ingle-particle binding energies. Hartree-Fock method,parity mixing. 
1i) 〈KE WORDS〉NUCLEAR STRUCTURE $\{+106\},\{+108\},\{+110\} \mathrm{Cd}$; calculated levels, BC/I ). Pairing, quadrupole interaction.

Note: Nuclel are given in sequence following Toplc specification and the delimfter ';' is used before "calculated". The delimiter ';' w111 be used after all calculated quantitles have been specifled and before any deduced items are enumerated. The comment statements regarding model, interactions etc. will follow after the delimiter '.'

iii) A definite mass or mass range speciflcation can be use tefore delimiter ';' and after topic spectfication.

$\langle$ KE WORDS $>$ NUCLEAR STRUCTURE $A=42$; calculated. ..... ; deduced........

$\langle$ KEYWORDS $>$ NUCLEAR STRUCTURE $A=42-48$; calculated $\ldots \ldots$; deduced $\ldots \ldots \ldots$.

TOPic: NUCLEAR MOMENTS:

Incluston criterla

Hyperfine structure, Isotope shift, mesic X-rays, isomer shift

information. Both experimental and theoretical articles are coded. The format is similar to RADTOACTIVITY entries.

Coding procedure:

i) 〈KE W ORDS〉NUCLEAR MOMENTS $\{+131\},\{+132\} \mathrm{Cs}$; measured hfs, a,b; deduced |m, quad rupole moment. 
ii) 〈KE WORDS〉NUCLEAR MOMENTS $\{+144\},\{+148\}$ Sm; measured muonic X-rays; deduced nuclear charge distribution parameters. $\{+144\},\{+148\}$ Sm level deduced quad rupole moment.

TOPIC: COMPILATION

Inclusion Criteria: any evaluation of nuclear structure, radioactivity data. Coding Procedure:

i) 〈KE WORDS〉COMP ILATION A=16; compiled, evaluated structure data.

ii) 〈KE WORDS〉COMPILATION $\{+197\} \mathrm{Ir},\{+197\}$ Pt; compiled, evaluated structure data.

TOPIC: ATOMIC PHYSICS

Inclusion Criteria: Mesic atoms, charged-particle induced X-ray emission, ionization probabilities etc.

Coding Procedure:

Format could be either as in NUCLEAR REACTIONS/RADIOACTIVITY/NUCLEAR MOMENTS.

i) کKE WORDS $>$ ATOMIC PHYSICS $\mathrm{Pb}(\mathrm{p}, \mathrm{X}), \mathrm{E}=0.9-3 \mathrm{MeV}$; Dy\{ $\mathrm{P}, \mathrm{X}), \mathrm{E}=0.6-3 \mathrm{MeV}$; measure d $Z$ (L X-ray), I( $L$ X-ray), production $\mid s$.

ii) $<K E$ WORDS>ATOMIC PHYSICS, Mesic Atons $\{+181\} \mathrm{Ta},\{+209 \mid \mathrm{Bi}$; calculated pionic s hifts, widths. Energy dependent optical potential. 
TOpic: ATOMIC MASSES

Inclusion Criteria:

A direct measurement, calculation or compilations of Atomic Masses are Included.

Coding Procedure:

1) 〈KE WORDS $>$ ATOMIC MASSES $\{+3\} \mathrm{H},\{+3\} \mathrm{He}$; measured mass difference. Mass spect rometer.

ii) 〈KE WORDS〉ATOMIC MASSES A=3-50; compiled, evaluated atomic mass data.

\section{MULTIPLE TOPIC KE WORDING}

Article may contain information on more than one topic.

For example a Nuclear Reaction studied, evidence for Radioactive Nuclei

deduced and their properties Investigated. Then the following will appear as one entry.

〈KE WWORDS〉NUCLEAR REACTIONS U,Th, $\mathrm{AU}, \mathrm{Ta}(\mathrm{p}, \mathrm{X}), \mathrm{E}=1 \mathrm{GeV}$; measured $\mathrm{E}\{\mathrm{a}, \mathrm{T}\{\alpha / 2\}$ of $\mathrm{spa}$ llation, fragmentation products; deduced reaction mechanism. Helium jet recoil product separation.

〈KE YWORDS>RADIOACTIVITY $\{+150\},\{+151\}$ Dy $,\{+152\},\{+152 \mathrm{~m}\} \mathrm{Ho}(\mid \mathrm{a}),(\mathrm{EC}),(\mid \mathrm{b}\}+\})$ [from $\mathrm{U}, \mathrm{Th}, \mathrm{Au}, \mathrm{Ta}(\mathrm{p}, \mathrm{X}), \mathrm{E}=1 \mathrm{GeV}\}$; measured $\mathrm{E} \mid \mathrm{a}, \mathrm{T}\{1 / 2\}$. Helium jet recoil product separation. 


\section{Li terature Coverage}

About 60-65 Journals from all parts of the world are scanned for information on major Topics of interest (Secs. II, III) and coded. These are the Primary sources. In addition, relevant information from Secondary sources such as Laboratory Reports, Conference Proceedings, Thesis etc. Is also coded. A list of Journals and Reports routinely scanned at NNDC is given in Sec. V Appendix $C$. 


\section{Appendices}

Appendix A: Character Sets to Be Used for Nuclear Structure References

The Nuclear Structure References file uses a part of the extended 8-BIT EBCDIC character set previously defined by ORNL Nuclear Data Project. Attached are three character sets which have been defined and avilable to recipients of the Nuclear Structure References file. Only those characters defined in the 8BIT EBCDIC system are permitted. One new character, a superscript ' $g$ ' has been defined. Several unused or little used characters have been eliminated.

Two other sets are defined for users who do not have 8-BIT character capability on their computers. These are 7-BIT system with control characters to get superscripit, subscript and other nonstandard characters. This system is used internally at NNDC and is available in standard 8-BIT EBCDIC. Finally there is a 6-BIT system in which superscripting, subscripting and nonstandard characters are not allowed. The 8-BIT and 7-BIT systems are compatible and no information is lost translating from one to another. The 6-BIT system represents a degradation of the information in the file. The mapping from 7-BIT to 6-BIT is described 1 ater in this document. 
Appendix A 
Decimal Bexadecimal Character

Decimal Fexádecimal Character

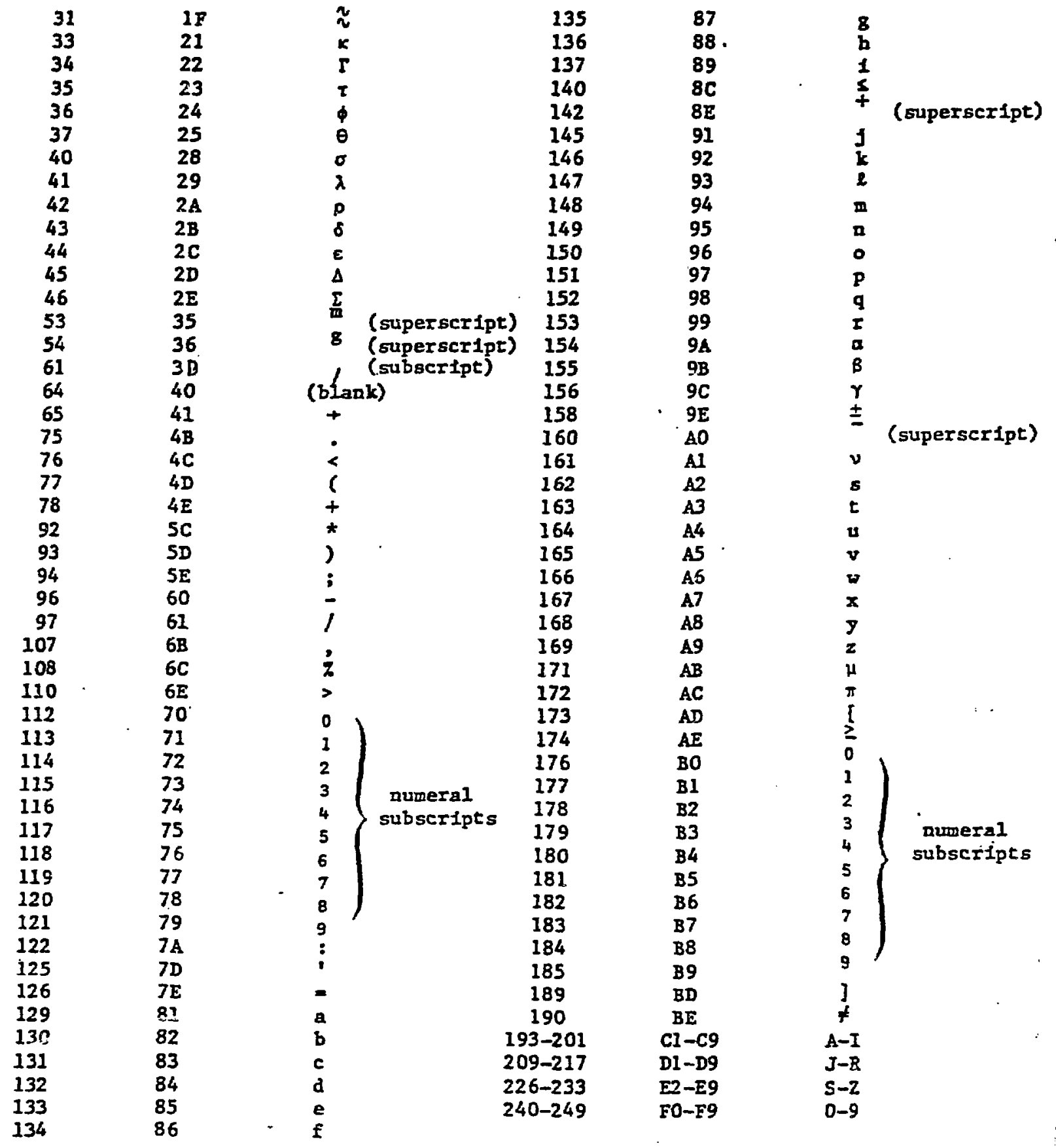


Appendix A

Extended 7-Bit Ascil set

STANDARD AND II ALTHRHATE GUARACTER SETS

\begin{tabular}{|c|c|c|c|c|c|c|c|c|c|c|c|c|c|c|c|c|}
\hline \multirow{3}{*}{$\frac{0 \text { otal } 1}{0.06 x}$} & \multirow{2}{*}{\multicolumn{2}{|c|}{$\frac{x 10}{(b \operatorname{lanh})}$}} & \multirow{2}{*}{\multicolumn{2}{|c|}{$x \times 1$}} & \multirow{2}{*}{\multicolumn{2}{|c|}{$\frac{x \times 2}{\text { "(overacora) }}$}} & \multicolumn{2}{|c|}{$\times \times 3$} & \multicolumn{2}{|c|}{$x \times 4$} & \multicolumn{2}{|c|}{ xxs } & \multicolumn{2}{|c|}{ Xx6 } & \multicolumn{2}{|c|}{$\boldsymbol{x y}$} \\
\hline & & & & & & & \multirow{2}{*}{1} & \multirow{2}{*}{1} & \multirow{2}{*}{$\frac{1}{1}$} & \multirow{2}{*}{1} & \multirow{2}{*}{ 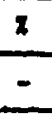 } & \multirow{2}{*}{$\frac{1}{7}$} & \multirow{2}{*}{1} & \multirow{2}{*}{ 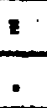 } & \multirow{2}{*}{1} & \multirow{2}{*}{$\frac{\text { (dugrea) }}{4}$} \\
\hline & 1 & 4 & ) & + & 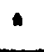 & $\left(t 1^{\top} e_{e}\right)$ & & & & & & & & & & \\
\hline $06 x$ & 0 & & 1 & & 2 & & 3 & & 4 & & 5 & & 6 & & 1 & \\
\hline $07 x$ & 8 & & 9 & & 1 & + & 1 & $\ddagger$ & 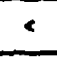 & $\leq$ & - & 1 & $>$ & $\geq$ & 1 & $x$ \\
\hline $10 x$ & $e$ & $\bullet$ & $A$ & $A$ & 8 & 1 & C & 月 & D & $\Delta$ & $\nabla$ & 8 & $F$ & 1 & 6 & $\mathbf{r}$ \\
\hline $11 x$ & $n$ & $x$ & $I$ & $\mathbf{I}$ & $J$ & & $\mathbf{K}$. & $x$ & $\mathbf{L}$ & $A$ & K & H & $n$ & $n$ & 0 & 0 \\
\hline $12 x$ & $\mathbf{P}$ & A & $\mathbf{q}$ & $\theta$ & $\mathbf{n}$ & $P$ & $\mathbf{s}$ & $\tau$ & $\mathbf{I}$ & $\mathbf{I}$ & $\mathbf{0}$ & 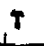 & $\mathbf{v}$ & $\nabla$ & $\mathbf{v}$ & a \\
\hline $13 x$ & $x$ & I & 1 & 7 & 2 & 2 & 1 & 1 & (bac) & & 1 & 1 & - & 1 & $=$ & 1 \\
\hline $\operatorname{lax}$ & $\checkmark$ & 2 & 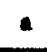 & $a$ & $b$ & 1 & c & $n$ & d & 1 & $\bullet$ & c & 1 & 1 & 8 & $r$ \\
\hline $83 x$ & h & $x$ & 1 & 2 & 1 & & $\mathbf{k}$ & $x$ & 4 & $\boldsymbol{\lambda}$ & 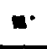 & 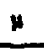 & $\mathbf{n}$ & $\checkmark$ & 0 & 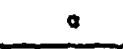 \\
\hline $16 x$ & $\mathbf{p}$ & 1 & 9 & 6 & $\Sigma$ & p & 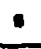 & 0 & $\mathbf{t}$ & $T$ & $v$ & $v$ & 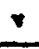 & 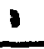 & 4 & 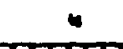 \\
\hline $11 \pi$ & $x$ & E & $y$ & 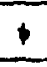 & 8 & 5 & & & & & & & & & & \\
\hline
\end{tabular}

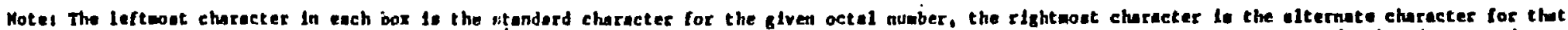

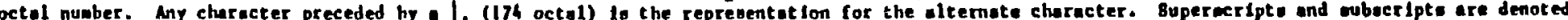

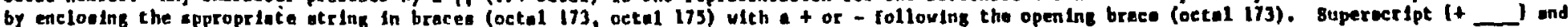
oubscript 10 


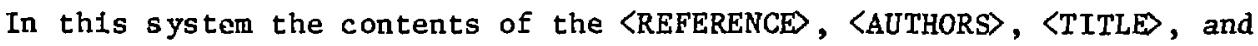
〈KE WWORDS> records are the only records affected by the degradation from the 7BIT to the 6-BIT character set.

The rules for this conversion are as follows:

1. All lower case goes to upper case.

2. All subscript numerals become standard numerals.

3. All superscript numerals become standard numerals.

4. All Greek letters are spelled out with a blank terminator if no blank, period, dash or similar follow the Greek character.

5. Superscript $m$ and $g$ become $\mathbb{M}$ and $G-$, respectively.

6.

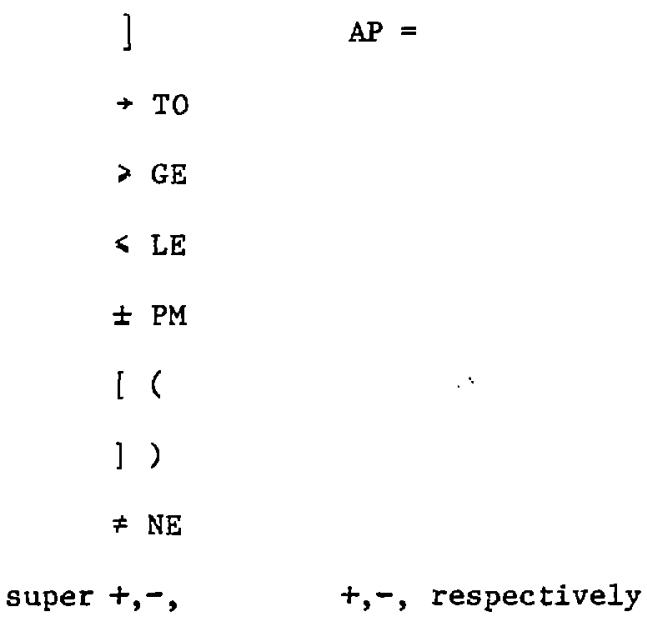


APPENDIX B: Accepted symbols and Explanations

$-33-$ 


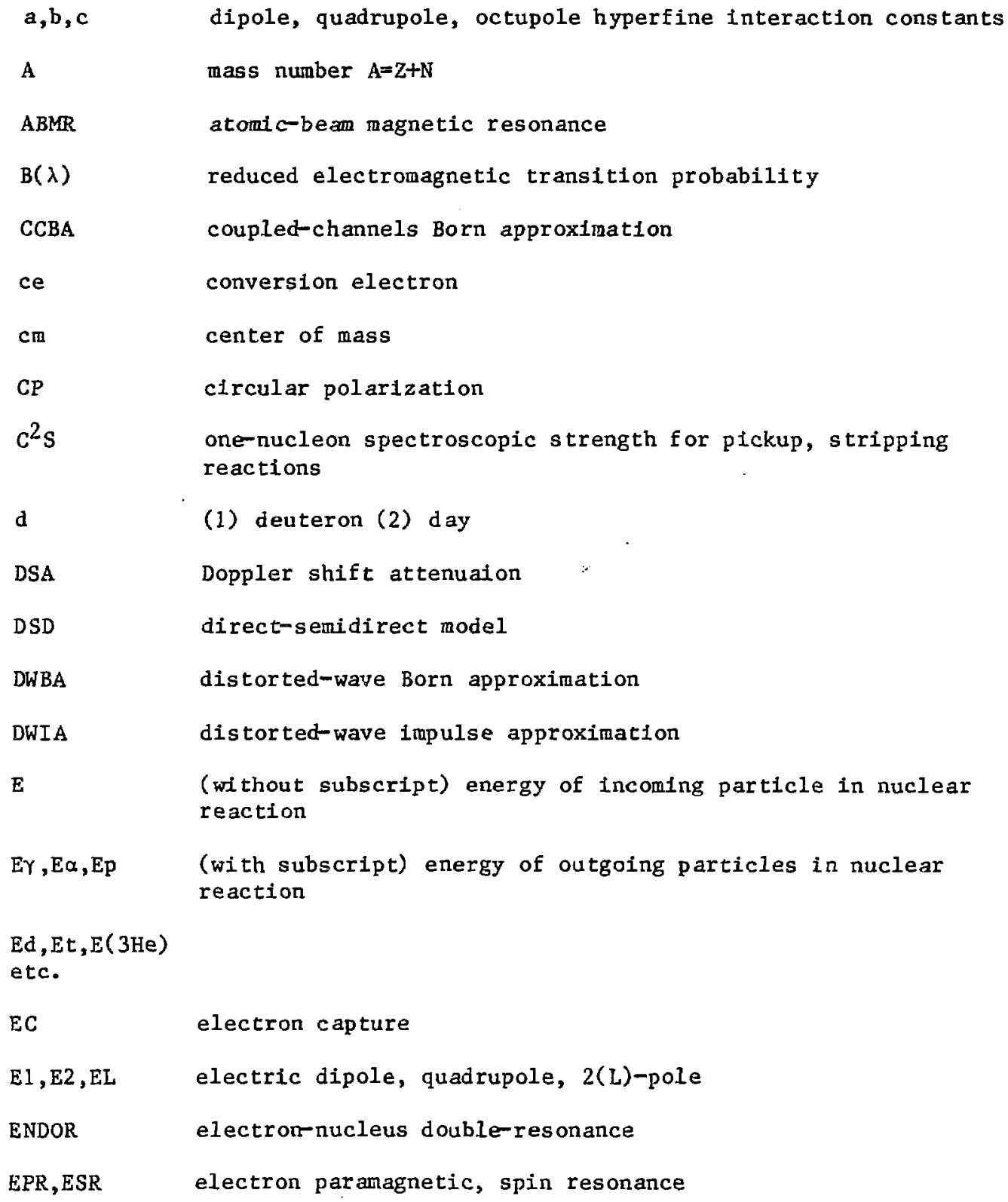




\begin{tabular}{|c|c|}
\hline EWSR & energy-weighted sum rule \\
\hline $\mathrm{F}$ & fission, fission fragment in a nuclear reaction \\
\hline fragment & fission fragment, spallation reaction product \\
\hline$g$ & gyromagnetic ration \\
\hline GDR & giant dipole resonance \\
\hline$G Q R$ & giant quadrupole resonance \\
\hline h & hour \\
\hline $\mathrm{H}$ & magnetic field \\
\hline $\mathrm{HF}$ & hindrance factor \\
\hline $\mathrm{HFB}$ & Hartree-Fock-Bogoliubov \\
\hline hfs & hyperfine structure \\
\hline I & (with subscript) intensity \\
\hline IAR & isobaric analog resonance \\
\hline IAS & isobaric analog state \\
\hline IB & internal bremsstrahlung \\
\hline ICC & internal-conversion coefficient \\
\hline IMPAC & ion implantation perturbed angular correlation technique \\
\hline IT & isomeric transition \\
\hline $\mathrm{J}$ & total angular momentum quantum number \\
\hline $\mathrm{K}$ & projection of $\mathrm{J}$ on nuclear symmetry axis \\
\hline $\mathrm{K}, \mathrm{L}, \mathrm{M}$ & $\mathrm{K}-$, L-, M-shell internal conversion \\
\hline$K / L$ & $\mathrm{~K}-$, L-conversion electron ratio \\
\hline $\mathrm{L}$ & $\begin{array}{l}\text { (1) orbital angular momentum (2) multipolarity (3) L-transfer } \\
\text { in stripping, pickup rections }\end{array}$ \\
\hline
\end{tabular}




\begin{tabular}{|c|c|}
\hline o & minute \\
\hline$M 1, M 2, M L$ & magnetic dipole, quadrupole, $2(\mathrm{~L})$-pole \\
\hline ms & millisecond \\
\hline $\mathbf{N}$ & neutron number, $N=A-Z$ \\
\hline NMR , NQR & nuclear magnetic, quadrupole resonance \\
\hline $\mathbf{P}$ & (with or without suffix) polarization \\
\hline PAC & perturbed angular correlation \\
\hline $\operatorname{pr}(\theta)$ & angular distibution of $\gamma-r$ ays with respect to a proton beam \\
\hline $\operatorname{pr}(t)$ & $\begin{array}{l}\text { time distribution of phontons with respect to a pulsed proton } \\
\text { bean }\end{array}$ \\
\hline PWBA & plane-wave Born approximation \\
\hline$Q$ & (1) reaction energy (2) disintegration energy \\
\hline$\not \mathrm{EC})$ & total disintegration energy in EC decay \\
\hline$\alpha \beta)$ & total disintegration energy in $B$-decay \\
\hline$Q \alpha$ & $" \quad " \quad " \quad " \alpha$-decay \\
\hline rms & root-mean-square \\
\hline RPA & randon-phase approximation \\
\hline s & second \\
\hline $\mathrm{s}$ & Spectroscopic factor \\
\hline $\mathrm{SF}$ & Spontaneous fission \\
\hline$t$ & (1) time (2) triton \\
\hline $\mathrm{T}$ & (1) isotopic or isobaric spin (2) temperature \\
\hline $\mathrm{T} 1 / 2$ & half-1ife \\
\hline TDA & Tamm-Dancoff approximation \\
\hline TDHF & \\
\hline
\end{tabular}




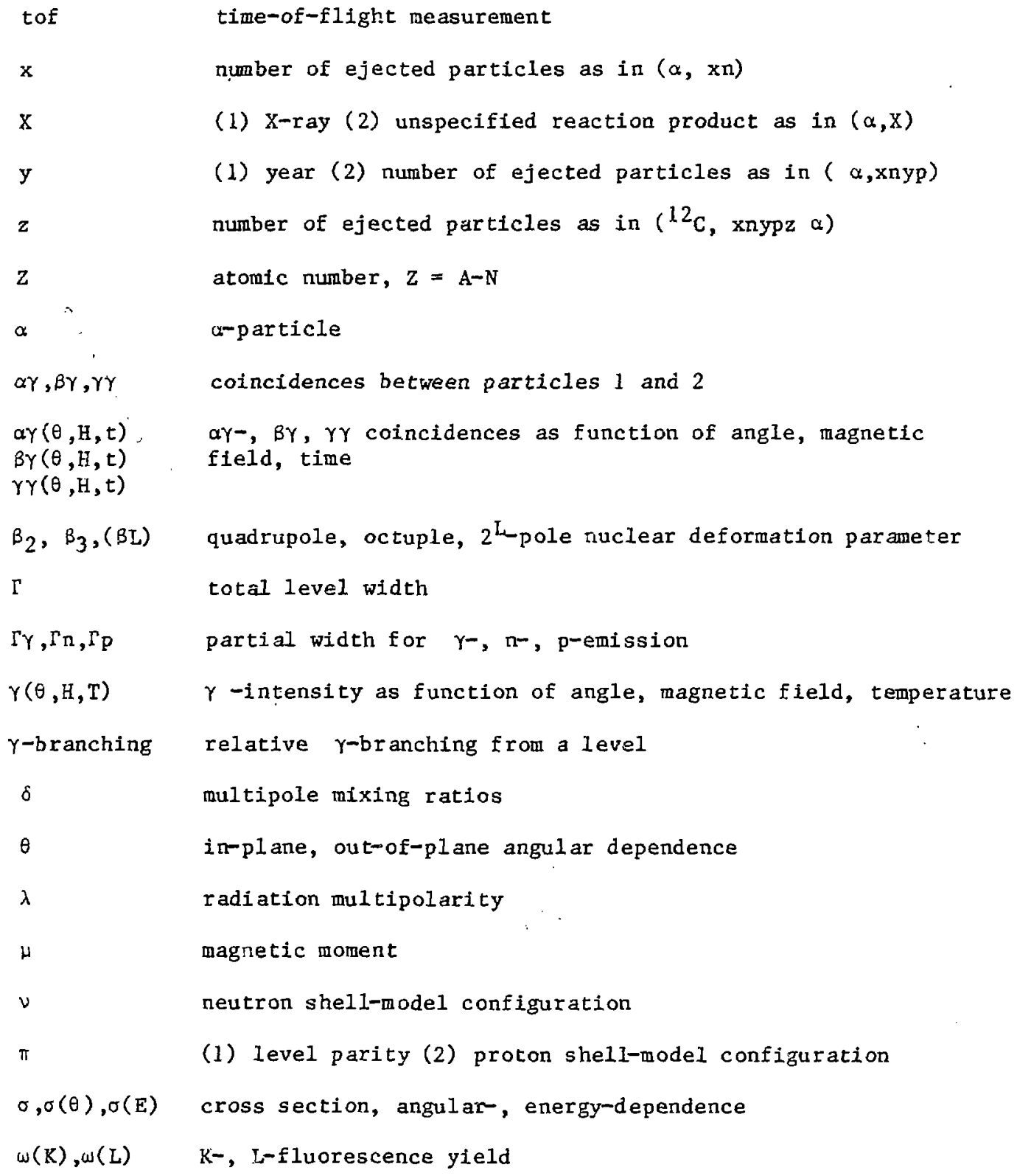


APPENDIX $C$ 


\section{Journals Scarned by the National Nuclear Data Center}

CODEN

AAFPA

ADNDA

AENGA

ANPHA

ANPYA

ANEND

APAHA

APASA

APNYA

$A P O B B$

ASSBA

ATKEA

ATKOA

ATPLB

AUJPA

BAPSA

BSRSA

CHDBA

CHJPA

C JPHA

CPHMA

CUSCA

CZYPA

DABBB

FECAA

FZKAA

HPACA

HYIND

IAAFA

IANFA

IJARA

I JOPA

I J PYA

INUCA

IUZFA

I VUFA

J I NCA

JNSTA

JOPQA

JPHG

JPQSA

JPSLB

JUPSA

XDVSA

XURAA

NCIAA

NCLTA

NDSBA

NSENA

NUI MA

NUKLA

NUPAB

NUSBA

PHBCD

PHCAA

PHSTB
JOURNAL

Ann. Acad. Scl. Fenn., Ser. $A$ vi

At. Data Nucl. Dets Tables

At. Enert.

Ann. Phys. (Paris)

Ann. Phys. (Leipzit)

Ann. Nucl. Eneray

Acta Phya.

Acta Phys. Austr.

Ann. Phys. (New York)

Act: Phys. Pol. B

Ann. Soc. Sei. Brux. Ser. 1

Atomkernenergie

ATOMKI Kozlem.

Acte Phys. Pol. A

A ust. J. Phys.

Bull. Amer. Phys. Soc.

Bull. Soc. Roy. Sci. Liege

C. R. Acad. Sci. . Ser. B

Chin. J. Phys. (Pokjng)

Can. J. Phys.

Commentat. Phys. -Math.

Curr. Sci. (India)

Czech. J. Phys. B

Diss. Abstr. Int. . B

Fiz. Elem. Chastits At. Yadra

Fizika

Helv. Phys. Acta

Hyperfine Interactions

Izv. Akad. Nauk Arm. SSR, Ser. Fiz.

Izv. A kad. Nauk SSSR. Ser. Fiz.

Int. J. Appl. Radiat. Isotop.

Indian J. Pure Appl. Phys.

Indian J. Phys.

Inorz. Nucl. Chem. Lett.

IzY. Akad. Nauk Uzb. SSR, Ser. Fiz. -Mat. Nauk

1zv. Vyash. Ucheb. Zaved. . Fiz.

J. Inorg. Nuel. Chem.

-J. Nucl. Sei. Technol.

J. Phys. (Paris)

J. Phys. (London), G

J. Phys. (Paris), Suppl.

J. Phys. (Paris), Lett.

J. Phys. Soc. Jpr.

Kel. Dan. Vidensk. Selsk. Mat. -Fys. Medd.

Annu. Rep. Res. Reactor inst. Kyoto Univ.

Nuovo Cim. A

Lett. Nuovo Cim.

Nucl. Data Sheets

Nucl. Sci. Eng.

Nucl. Instrum. Methods

Nukleoniks

Nucl. Phys. A

Nucl. Sci. Appl. , Ser. B

Physica, B, C

Phys. Can.

Phys. Ser. 


PHYAD
PLRAA
PLRBA
PPSSA
PRAMC
PREAA
PRLTA
PRVCA
PTPXA
PTPSA
PYLAA
PYLBB
PZETA
RAAA
RAISA
RMXFA
RPHAA
RRALA
RRPQA
SAPHD
SCEFA
UFZHA
YMUFA
YAFIA
ZENAA
ZETFA
ZPAAD
ZPBBD

PHYAD

PLRAA

PPSSA

PRAMC

PREAA

PRVCA

PTPXA

PTPSA

PYLBB

PZETA

RAACA

RMXFA

RPHAA

RRALA

RRPQA

SCEFA

UFZHA

ZENAA

IPAAD

ZPBBD

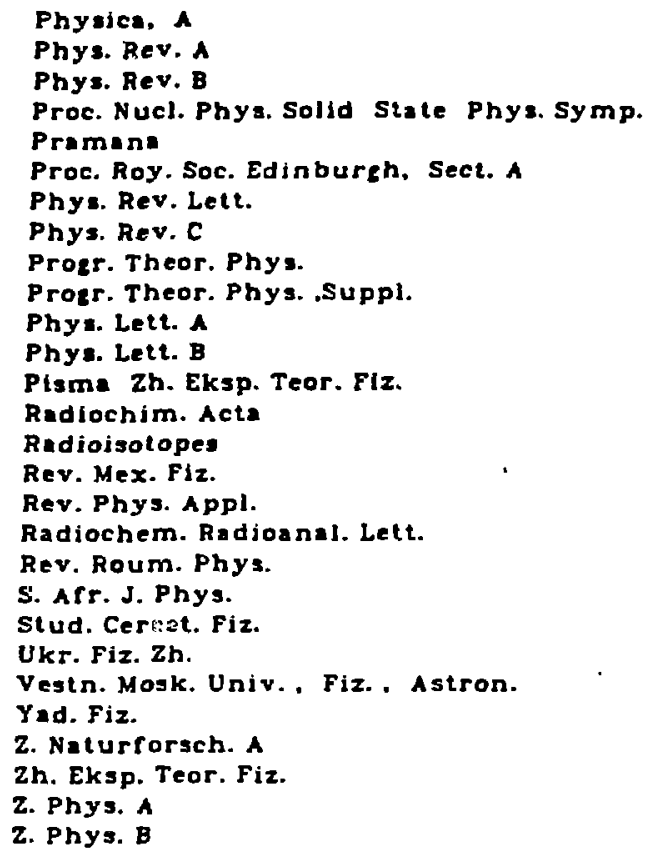

Reports Scanned by the National Nuclear Data Center

\section{CODE}

AECL

AN L

BNL

INDC

INS

I PCR

IPN

$15 N$

JINR

JUL-SPEZ

JYFL

LA

LBL

NEANDC

ORNL

UTTAC

ZFK
AEPORT

At. Energ. Canada Ltd. Prog. Rept.

Argonne Nat. Lab. Rept.

Brookhaven Nat. Lab. Rept.

Intern. Nucl. Data Committee Rept.

Inst. Nucl. Studies, Tokyo

Inst. Phys. Chem. Res. Rept. . Japan

Inst. Phys. Nucl. . Paris

Inst. Sci. Nucl. , Grenoble

Joint Inst. Nucl. Res. , Dubna

Inst. fur Kernphysik. Julich

Univ. Jyvackyla. Finland

Los Alamos Sci. Lab. Rept.

Lawrence Berkeley Lab. Rept.

Nucl. Energ. Agency Nucl. Data Comm. Rept.

Oak Ridge Nat. Lab. Rept.

Univ. Tuukuba Tandem Accelerator Center. Japan

Zentralinstitut rur Kernforschune. Dresden 